\title{
Acceptability and Feasibility of Mifepristone-Misoprostol For Menstrual Regulation in Bangladesh
}

\begin{abstract}
CONTEXT: Annually, more than 700,000 women turn to menstrual regulation, or uterine evacuation with vacuum aspiration; many more resort to unsafe abortion. Using pills for the evacuation of the uterus could increase women's access to safe menstrual regulation services and reduce the high levels of abortion-and menstrual regulationrelated morbidity in Bangladesh.
\end{abstract}

METHODS: At 10 facilities in Bangladesh, 651 consenting women who were seeking menstrual regulation services and who were 63 days or less past their last menstrual period received $200 \mathrm{mg}$ of mifepristone followed 24 hours later by $800 \mathrm{mcg}$ of buccal misoprostol, administered either at home or in the clinic. Prospective data were collected to determine women's experience and satisfaction with the procedure, menstrual regulation outcome, and the human and physical resources required for providing the method. Focus group discussions were conducted with a purposively sampled group of service providers at each site to understand their attitudes about the introduction of menstrual regulation with medication.

RESULTS: The majority of women (93\%) with known menstrual regulation outcomes evacuated the uterus without surgical intervention. Overall, most women (92\%) were satisfied with use of pills for their menstrual regulation. Providers faced initial challenges and concerns, particularly related to the additional counseling requirements and lack of control over the final outcome, but became more confident after successful use of the medication regimen.

CONCLUSIONS: Mifepristone-misoprostol can be safely offered within existing menstrual regulation services in urban and periurban areas in Bangladesh and is highly acceptable to women. Providers' initial concerns diminish with increased experience with the method.

International Perspectives on Sexual and Reproductive Health, 2013, 39(2):79-87, doi: 10.1363/3907913

Menstrual regulation, or the evacuation of the uterus of a woman at risk of being pregnant to ensure a state of nonpregnancy, was introduced in Bangladesh in the 1970s in the context of a restrictive abortion law, in part to reduce maternal morbidity and mortality associated with unsafe abortion. ${ }^{1,2}$ The introduction of menstrual regulation also coincided with the Bangladesh Liberation War, during which 200,000-400,000 Bangladeshi women were the victims of rape; the new government allowed abortions for those who had become pregnant. ${ }^{3}$ Under the Bangladesh Menstrual Regulation program, manual vacuum aspiration is provided free of cost at primary, secondary and tertiary levels of the public-sector health system. Menstrual regulation services are also provided, for a fee, in some nongovernmental organization clinics and privatesector clinics in Bangladesh. Physicians are permitted to perform menstrual regulation up to 10 weeks' amenorrhea and midlevel providers (family welfare visitors or paramedics) up to eight weeks' amenorrhea. By the end of 2011, approximately 10,600 doctors and 7,200 family welfare visitors and paramedics had been trained in the provision of menstrual regulation. ${ }^{4}$ Government Management Information System data report 200,000 menstrual regulation cases each year, but this is generally considered to significantly underreport the actual number of cases; a recent study estimated 653,000 per year. ${ }^{5}$

Although menstrual regulation services have been decentralized and are officially available free of charge in the public sector, many women lack access to these services. In a recent study, Bangladeshi women described a range of socioeconomic barriers that affected their access to menstrual regulation services and contributed to delays in obtaining these services. ${ }^{6}$ In that study, cost, social stigma and fear of the procedure were identified as the main obstacles to obtaining safe menstrual regulation services. The cost barrier is pervasive. One study found that among menstrual regulation clients, only $11 \%$ of women reported receiving free services, even though services obtained in the public sector are supposed to be free of cost. ${ }^{7}$ Additional costs are incurred if the woman is beyond the legal limit for number of days since last menstrual period, and these costs tend to increase with gestational age.

Low levels of education and lack of awareness of menstrual regulation services also affect access. Most women report unofficial sources such as relatives, friends and neighbors as their main source of information about menstrual regulation; only $9 \%$ of menstrual regulation users were told about services by trained family planning work-
By Anadil Alam, Hillary Bracken, Heidi Bart Johnston, Sheila Raghavan, Noushin Islam, Beverly Winikoff and Laura Reichenbach

Anadil Alam is senior research investigator; Noushin Islam is research investigator; and Laura Reichenbach is director, Center of Reproductive Health-all at icddr,b, Dhaka, Bangladesh.

Hillary Bracken is director, Sheila Raghavan is program associate and Beverly Winikoff is presidentall at Gynuity Health Projects, New York. Heidi Bart Johnston is senior scientist, Swiss Tropical and Public Health Institute and University of Basel, Switzerland. 
ers. ${ }^{8-10}$ Barriers to safe and legal menstrual regulation may lead women to turn to illegal and unsafe abortion procedures. According to a recent study, more than 230,000 women were treated for complications of unsafe abortion and menstrual regulation in $2010,{ }^{5}$ the study identified more than 78,000 women treated for complications related to menstrual regulation in that year. Because not all women who develop complications obtain treatment, the true number of women experiencing complications from menstrual regulation and unsafe abortion is expected to be much higher. Incremental costs to the health system of managing complications of unsafe abortion are estimated to surpass US\$1.6 million annually. ${ }^{11}$

Use of pills for the evacuation of the uterus, in lieu of surgical intervention, may help increase access to safe menstrual regulation services and potentially reduce the high levels of abortion and menstrual regulation-related morbidity in Bangladesh. Mifepristone is an antiprogestin licensed for pregnancy termination in more than 40 countries around the world. ${ }^{12}$ Mifepristone followed by a prostaglandin analog, most commonly misoprostol, has been shown to be safe and effective up to nine weeks (63 days) of pregnancy ${ }^{13}$ and is the method of abortion recommended by the World Health Organization. ${ }^{14}$ However, the acceptability and feasibility of this method for women and providers have not previously been examined in Bangladesh. This study assessed the feasibility and acceptability of a simplified mifepristonemisoprostol regimen for menstrual regulation in 10 facilities in Bangladesh. The ethical review board at icddr,b approved the protocol prior to the start of the study.

\section{METHODS}

Women seeking menstrual regulation services were recruited for a trial of medication menstrual regulation at 10 centers in two phases between July 2009 and April 2010. In the first phase of the research, July-October 2009, women were recruited at three tertiary-care facilities located in Dhaka city. Two of these sites are training centers for menstrual regulation services located in government hospitals: Reproductive Health Services Training and Program (RHSTEP) Sir Salimullah Medical College \& Mitford Hospital and RHSTEP Dhaka Medical College Hospital. The third site, the Marie Stopes Premium Clinic, is a 24-hour private facility offering menstrual regulation services. In all phase-one sites, physicians handled almost all aspects of treatment, making eligibility assessments, administering medication and evaluating the success of the menstrual regulation. During the second phase of the research, from December 2009 to April 2010, women were recruited at seven nongovernmental sites in urban and periurban areas outside Dhaka city (Bangladesh Association for Prevention of Septic Abortion [BAPSA], Gazipur; BAPSA, Mirpur; Bangladesh Women's Health Coalition, Narayanganj; Family Planning Association of Bangladesh [FPAB], Chittagong; FPAB, Rajshahi; Marie Stopes, Sylhet; RHSTEP, Mymensingh). At the phase-two sites, menstrual regulation services were provided by physicians and paramedics. In all, 651 women were recruited for the study. Given the lack of differences in the primary outcome between the two study phases, the data were merged for analysis. However, we report comparisons of secondary outcomes (side effects, bleeding) in which significant differences were found.

All women seeking menstrual regulation services at participating clinics were asked if they wanted to enroll in a trial of medication menstrual regulation. Women were eligible if they were 18 years or older; amenorrheic for up to nine weeks on the day of mifepristone administration; in good health, with no contraindications to mifepristone or misoprostol; willing to provide a urine sample; and able and willing to provide a telephone number for the purposes of follow-up. Amenorrhea was calculated using standard methods for menstrual regulation: the date of last menses and bimanual exam. In phase-one sites, the exam and assessment were performed by physicians exclusively. In phase-two sites, midlevel providers performed $7 \%$ of the assessments. Although ultrasound could be used if the provider needed to rule out pathology or unexplained discrepancies between other methods of eligibility assessment, there were no cases in which this was considered necessary. Women who elected to take part and met the study criteria were enrolled after giving informed consent, by providing either their signature or their thumbprint. Women were compensated 150 Taka (US\$1.84) to cover the cost of transportation to the study clinic for the follow-up visit.

Pregnancy testing is not routinely performed prior to menstrual regulation in Bangladesh. However, to facilitate comparisons with international experience with such regimens for medication abortion, all women were asked to provide a urine sample for laboratory analyses prior to administration of mifepristone. Almost all women ( $\mathrm{N}=650$ ) provided a sample. Each sample was labeled with a unique study ID number and stored frozen at the study site. After a woman completed the exit interview, the sample was transported by icddr,b staff to the organization's laboratory and a pregnancy test was performed on the sample using the Genzyme ${ }^{\mathrm{TM}}$ HCG Card pregnancy test.

After oral administration of $200 \mathrm{mg}$ of mifepristone at the clinic, most women were offered the choice of either returning 24 hours later to take $800 \mathrm{mcg}$ misoprostol or of taking the misoprostol at home. The first 5-10 women recruited at each clinic were required to return to take the misoprostol on site to increase provider familiarity with the drug's administration; in all, 81 women were required to take the misoprostol in the clinic. All women were counseled to take the misoprostol buccally, i.e., by holding two tablets between each cheek and gum for about 30 minutes. Women were given a mild analgesic (two 500-mg paracetamol tablets) to take as needed. All participants received instructions on where to seek around-the-clock help in case of concerns or emergencies.

Women were asked to return to the clinic 10-14 days following their initial visit to determine the success of the procedure. At the follow-up visit, providers took a short history and asked women to describe the bleeding experi- 
enced after mifepristone and misoprostol administration. A bimanual examination was performed to assess uterine size and confirm any change since the initial exam. Providers also confirmed and documented any symptoms suggesting a potential complication, including tenderness on exam, fever, pain or excessive blood loss. In phase-one sites, all of the follow-up exams were performed by a physician. In phasetwo sites, $23 \%$ were performed by a midlevel provider.

If the results of the follow-up exam confirmed a state of nonpregnancy and no symptoms suggested a need for additional care, the procedure was considered successful. According to the study protocol, if the provider was not certain of the outcome following the clinical exam, ultrasound could be used to evaluate the success of the procedure, but there were no cases in which this was considered necessary. However, in one case, at an unscheduled visit eight days after misoprostol administration, an ultrasound was performed because of a suspected ectopic pregnancy; an ectopic pregnancy was confirmed and appropriate management was provided.

If the provider identified an increase in uterine size consistent with an ongoing pregnancy at the follow-up visit, the procedure was considered to have failed and a manual vacuum aspiration was performed. If the provider confirmed a return of the uterus to prepregnancy size, but was not confident that the uterus had been emptied, the woman was offered a surgical intervention (uterine evacuation) or an additional follow-up visit (with or without administering another dose of $800 \mathrm{mcg}$ buccal misoprostol), depending on the evaluation of the clinician and the choice of the woman. Women could request a surgical evacuation at any time during the process.

When the procedure was complete, participants were asked a series of questions assessing their experiences of the procedure and their satisfaction with the method. Family planning counseling and methods were provided per standard practice at the study sites.

\section{Focus Group Discussions}

At the conclusion of the study, a focus group discussion was conducted at each site with a purposively sampled group of service providers, including doctors, counselors, paramedics and clinic administrative staff. There were 10 focus group discussions, with 40 participants, in all; each group discussion included four people and lasted approximately 30-45 minutes. A semistructured discussion guide focused on providers' attitudes about mifepristonemisoprostol for menstrual regulation since study implementation and perceived barriers to and advantages of its use in existing services. All participants provided written informed consent. Discussions were conducted by a moderator trained in qualitative research methods.

All focus group discussions were recorded on audiotape and a detailed transcript was prepared after each discussion; notes were taken during the focus group discussions to supplement the transcripts. The transcripts were reviewed by the researchers to identify key themes and
TABLE 1. Selected social and demographic characteristics of women seeking menstrual regulation with medication at 10 facilities in Bangladesh, 2009-2010

\begin{tabular}{lc} 
Characteristic & Mean or \\
& $(\mathrm{N}=651)$ \\
\hline Means & \\
Age in yrs. (range) & $27(17-45)$ \\
Yrs.of school attended & $10(4.7)$ \\
Minutes to travel to clinic from home & $33(24)$ \\
& \\
Percentages & \\
Attended school/university/madrasa & 93.9 \\
Currently married & 99.5 \\
Primigravida & 23.2 \\
Amenorrhea in wks. & \\
$\leq 6$ & 51.9 \\
$>6-7$ & 35.0 \\
$>7-8$ & 12.3 \\
$>8-9$ & 0.8
\end{tabular}

Note: Unless otherwise noted, figures in parentheses are standard deviations.

subthemes. A constant comparative approach was used, in which the responses from different respondents were compared to identify similarities and differences. Thematic analysis of data was done manually using content analysis.

\section{Analyses}

The principal analysis compared the menstrual regulation outcomes in the women recruited during the two phases of the study using merged data; there were no significant differences between the two study phases. Thus, data are presented for the full sample. The chi-square or Fisher exact test, as appropriate, was used for independent nominal data, and statistical significance was defined at $\mathrm{p} \leq .05$. Data were analyzed using SPSS version 15.0.

The success of the mifepristone-misoprostol regimen was defined as completion of the menstrual regulation without the need for a surgical evacuation. Studies on this regimen in other settings have found success rates of 9598\%. ${ }^{15-17}$ Studies have shown slightly lower success rates when medication abortion is first introduced into existing services because providers with less experience with the procedure may be more likely to intervene surgically rather than practice expectant management when the uterus is not completely emptied. ${ }^{18}$ An efficacy rate of $85 \%$ would be feasible for implementation in clinics in Bangladesh, as the method would present a viable alternative to the standard vacuum aspiration services currently offered in these settings. To have $80 \%$ power (alpha $=.05$ ) to demonstrate that the regimen was $90 \%, \pm 5 \%$, effective, we calculated that we would need to enroll at least 138 women in each phase of the study. This sample size also allowed us to test whether at least $85 \%$ of Bangladeshi women enrolled in the study were "satisfied" or "very satisfied" with the method.

\section{RESULTS}

The mean age of the women enrolled in the study was 27 years (Table 1). Almost all women were married (99.5\%), and most had attended school, university or madrasa 


\begin{tabular}{|lc|}
\hline $\begin{array}{l}\text { TABLE 2. Percentage distribution of menstrual regulation } \\
\text { procedures with medication, by outcome }\end{array}$ & $\begin{array}{l}\% \\
\text { Outcome }\end{array}$ \\
& $(\mathrm{N}=629)^{*}$ \\
\hline Success & $\mathbf{9 2 . 7}$ \\
& $\mathbf{7 . 3}$ \\
Surgical evacuation needed & 1.0 \\
Increase in uterine size consistent with ongoing & 5.1 \\
$\quad$ risk of pregnancy & 0.5 \\
Debris in the uterus & 0.3 \\
Heavy bleeding & 0.5 \\
Woman's request & 100.0 \\
No bleeding after misoprostol administration & \\
Total & \\
\hline *Excludes 22 women lost to follow-up. tIncludes one woman diagnosed \\
with ectopic pregnancy at unscheduled visit after mifepristone- \\
misoprostol administration.
\end{tabular}

(94\%). The mean travel time to the clinic was 33 minutes. For almost one-quarter of the women, the pregnancy was their first. Slightly more than half of the women had amenorrhea of no more than six weeks (52\%).

\section{Menstrual Regulation Outcomes}

Most (93\%) of the 629 women with known menstrual regulation outcomes evacuated the uterus without surgical intervention (Table 2). There was no significant difference in the success rate for women who administered the misoprostol at home and those who received it in the clinic ( $93 \%$ vs. 90\%; p=.58; not shown).

For 46 women, the procedure failed and manual vacuum aspiration was required to complete the procedure (7\%). A manual vacuum aspiration was performed because of an increase in uterine size consistent with an ongoing risk of pregnancy in $1 \%$ of cases and because of incomplete emptying of the uterus in $5 \%$ of cases. For 27 women, these evacuations were performed at the follow-up visit (not shown). In the five remaining cases, the evacuation was performed at a second follow-up visit after either an additional dose of misoprostol (for two women) or expectant management (for three). Less than one percent of women $(0.5 \%)$ had a manual vacuum aspiration because of heavy bleeding; all of these women presented at the study site or a local referral hospital before the scheduled follow-up visit and received a dilation and curettage and blood transfusion.* Two women (0.3\%) requested a surgical evacuation at or before the follow-up visit. Three $(0.5 \%)$ returned to the clinic before their scheduled follow-up and reported no bleeding after misoprostol administration; in all these cases, the attending provider performed a surgical uterine evacuation.

Twenty women were given a second follow-up visit after the provider identified debris in the uterus at their followup visit. An additional 800-mcg buccal dose of misoprostol was provided for most of these women. Almost all women who received the additional medication had a successful procedure. Among the six women who received expectant management, two women needed no additional care, three women (included in the 32 surgeries above) eventually received a surgical evacuation and one woman was lost to follow-up after the second follow-up visit.

As expected, most women (94\%) reported that the bleeding experienced after misoprostol administration was similar to or greater than during menses (not shown). Substantial minorities reported nausea $(37 \%)$ or vomiting (24\%). About one-fifth of women reported having had mild fever, chills or weakness on the day of misoprostol administration, but in most cases these symptoms did not need treatment. Eight women in the phase-one sites reported itching of the palms on the day of misoprostol administration

The pregnancy test performed on the stored urine samples determined that most women (93\%) who had received mifepristone-misoprostol had been pregnant. The success rate of the subset of women with a positive urine pregnancy test (93\%) was the same as the success rate for the entire sample of women (93\%).

In 45 cases, the urine pregnancy test result was negative. The percentage of women with a negative pregnancy test varied widely across clinics (3-18\%). Among the women with a negative pregnancy test, slightly more than half (56\%) had been amenorrheic for 7-9 weeks since their last menstrual period at the time of mifepristone administration, according to bimanual exam and patient history. The remaining women (44\%) had been amenorrheic for six weeks or less.

Three women with a negative pregnancy test were lost to follow-up after mifepristone administration. Thirty-eight women who had a negative pregnancy test and who returned to the clinic at or before their follow-up visit were determined to have had a successful procedure on the basis of history and clinical exam. Four women with a negative pregnancy test eventually obtained a surgical evacuation. Two of these women underwent a manual vacuum aspiration after clinic staff identified an increase in uterine size consistent with an ongoing pregnancy at the followup exam (increased from six to nine and from seven to 10 weeks' amenorrhea, respectively). One woman, assessed as seven weeks from her last menstrual period at the time of mifepristone administration, returned to the clinic with heavy bleeding one day after misoprostol administration, and a surgical evacuation was performed at that time. One woman assessed as less than six weeks since her last menstrual period returned to the clinic two days after misoprostol administration. She reported no bleeding, and the attending provider elected to perform a surgical evacuation the same day.

\section{Protocol Adherence and Home Administration of Misoprostol}

Almost all women took the mifepristone and misoprostol as indicated and returned as scheduled for their followup visit (not shown). One woman reported taking the

*Dilation and curettage is the standard practice for management of in complete abortion at the referral hospitals. Blood transfusions are performed when justified by the clinical assessment. 
misoprostol early (i.e., less than 24 hours after taking the mifepristone), and 10 women reported holding the misoprostol in their cheeks for fewer than 30 minutes. None of these women required a surgical intervention to complete the menstrual regulation. Few women made unscheduled calls $(14 \%)$ or visits ( $2 \%)$ to the clinic.

Women who elected to take the misoprostol at home ( $N=540)$ cited several reasons for their choice, including ease or convenience (62\%), a preference for fewer clinic visits (47\%) and greater comfort with home administration $(33 \%)$. Women who were given a choice and who chose to take the misoprostol in the clinic $(\mathrm{N}=30)$ did so because they believed that they would receive better care (83\%), felt more comfortable (37\%), or found it more convenient or easier (30\%).

Most (73\%) of the women who took the misoprostol at home had someone with them at the time of misoprostol administration; for the majority of women, it was their husband $(47 \%)$ or mother $(10 \%)$.

Women were asked about their preference for place of misoprostol administration in the future. Women who chose to take the misoprostol at home were significantly more likely to say they would choose to do so in the future than women who chose to receive the prostaglandin in the clinic (home, 93\%; clinic, 59\%-p<.001).

\section{Acceptability of Menstrual Regulation with Medication}

Overall, most women (92\%) were satisfied with use of pills for their menstrual regulation (Table 3). The majority of both clinic and home users of misoprostol rated their experience as satisfactory or very satisfactory. Most women found the overall side effects associated with the method acceptable or very acceptable (90\%). About two-thirds of women $(67 \%)$ found the bleeding less than or the same as expected. Women's expectations about bleeding, pain and pain management differed across sites. Significantly more women at phase-two sites than at the phase-one sites reported that the bleeding was more than expected (37\% vs. $26 \%$; $<.001$ ). Most women (70\%) enrolled in each phase found the pain management provided adequate. However, more women in the phase-one sites than the phase-two sites found the pain medication insufficient (17\% vs. 9\%; $\mathrm{p}=.01-$ not shown). Almost all women reported that they would recommend using pills for menstrual regulation to a friend (93\%) or would prefer that method if they required another procedure (92\%).

At the follow-up visit, women were asked to report the best and worst features of using pills for menstrual regulation (Table 4). The majority of women reported that the best features of the method were that it avoided surgery and anesthesia (64\%) and was an easy, quick or simple treatment $(55 \%)$. The features of menstrual regulation with pills most often identified as the worst were the pain and cramps (44\%), anxiety or fear that the method would fail (26\%) and bleeding (23\%). Twenty percent of women said that there was no worst feature associated with menstrual regulation with pills.
TABLE 3. Percentage distribution of women who had a menstrual regulation with medication, by selected responses

Response

$(\mathrm{N}=629)^{*}$

Satisfaction

Very satisfactory or satisfactory $\quad 92.4$

Neutral

Unsatisfactory or very unsatisfactory

Overall side effects

Very acceptable or acceptable

Neutral

Unacceptable or very unacceptable

8.5
7.8
2.7

Bleeding

Less than expected $\quad 21.3$

Same as expected $\quad 45.9$

More than expected 31.6

Don't know/no bleeding $†$

Pain management

Adequate

Not adequate

69.8

No pain medication taken $\quad 17.8$

Total

100.0

*Excludes 22 women lost to follow-up. FFour women did not know and three reported no bleeding. Note: Percentages may not total 100.0 because of rounding.

\section{Acceptability Among Providers}

In the focus group discussions, the majority of all types of providers were open to and excited about learning a new procedure for menstrual regulation. As one observed:

"This is a nonsurgical method of menstrual regulation so it will become demandable among clients. The entire procedure was very much acceptable to both service providers and clients.... This is an easy procedure and it has minimum side effects."-Female medical officer, age 29, phase two, urban area

Yet other providers expressed an initial sense of trepidation about using medicine rather than manual vacuum as-

\begin{tabular}{|lc|}
\hline $\begin{array}{l}\text { TABLE 4. Percentage of women having a menstrual regula- } \\
\text { tion with medication who reported selected factors as the } \\
\text { best and worst features of the procedure } \\
\text { Feature }\end{array}$ & $\%$ \\
& $(\mathrm{~N}=629)^{*}$ \\
\hline Best & \\
Avoided surgery/anesthesia & 63.9 \\
Easy, quick, simple treatment & 54.7 \\
Successful,no complications & 17.2 \\
Private, confidential & 12.2 \\
Home administration of misoprostol & 7.8 \\
Little/no pain & 5.7 \\
None & 4.1 \\
Worst & \\
Pain, cramps & \\
Anxiety, fear of failure & 43.6 \\
Bleeding & 26.4 \\
Nausea, vomiting & 22.9 \\
Duration of procedure & 20.7 \\
Unsuccessful & 9.4 \\
Other side effects & 3.2 \\
Buccal misoprostol administration & 1.7 \\
None & 1.0 \\
\hline
\end{tabular}

*Excludes 22 women lost to follow-up. Note: Multiple answers were possible. 
piration. Providers, both doctors and counselors, were initially concerned about side effects, and some doctors and clinic staff had initial concerns that the medicine would not work properly because the medications were given buccally rather than vaginally, but these concerns were allayed after a few successful procedures were performed.

There was clear consensus among all types of providers that menstrual regulation with medication avoids infection and longer-term comorbidities associated with aspiration and other more invasive procedures. The most common justifications given by these providers for the use of pills for menstrual regulation were reducing infections and ensuring women's privacy and dignity. One provider noted:

"In my opinion, this new route on menstrual regulation will prevent pelvic inflammatory infection and related diseases that may occur [because of] unhygienic manual vacuum aspiration procedures.... I think this medical menstrual regulation procedure will [be a] great benefit to menstrual regulation service provision."-Female medical officer, age 45, phase one, urban area

However, the introduction of menstrual regulation with medication still posed some challenges. Counselors complained that menstrual regulation with medication required more counseling than a surgical procedure. As one said:

"...it was tough and time-consuming for us to make our clients understand about the whole procedure of menstrual regulation with medication and its physical consequences."-Female counselor, age 39, phase one, urban area

Counseling needs were also greater for women who had previously attempted self-induction using ineffective medications (such as Gynaecosid) acquired at pharmacies.

Some counselors mentioned difficulties in counseling women on buccal administration. (Approximately 1\% of women reported that buccal administration of misoprostol was the worst feature of menstrual regulation with pills.) Doctors confirmed that a few clients complained of discomfort and abrasions in the mouth, and that approximately $3 \%$ of women had not held the pills in their cheeks for 30 minutes as instructed. Several doctors explained that women had not complied with these directions because they did not like the taste of the misoprostol or were experiencing the morning sickness associated with early pregnancy.

Some providers, including doctors, counselors and paramedics, were anxious about waiting the 14 days until the follow-up visit to learn the results of the procedure. They said that an important challenge of the method was the loss of control over the final outcome. They observed that use of pills for menstrual regulation is not solely in the control of service providers, but depends on the client's ability to manage the procedure. This contributed to the doctor's overall anxiety about the outcome of the procedure. One provider noted:

"During the study, we were anxious about the response of the study patients. We were always anxious to hear any complication like bleeding, painful bleeding, spotting or any other problem [that] might occur after taking medicine at home. We were concerned about how we would solve and overcome if any physical problem occurred among study patients at night."-Male medical officer, age 51, phase two, urban area

Although generally supportive of the introduction of mifepristone-misoprostol into routine menstrual regulation services, some counselors were concerned about the implications of the widespread availability of the drugs. As one provider remarked,

"The main problem in Bangladesh is no monitoring of pharmacies. There is high chance of misuse of drugs if they are available in the local pharmacy. Medical menstrual regulation should be available in selected facilities, such as [nongovernmental organization] clinics and government hospitals-clinics where they can provide counseling [as well as]...emergency complication management services."-Female counselor age 46, phase one, urban area

One counselor doubted that women themselves could determine their eligibility for the procedure and underscored that there was a vital role for trained clinicians in the process. She noted:

"[Duration] of amenorrhea is very vital issue in medical menstrual regulation procedures. Rural Bangladeshi women in most cases [can] not tell accurately about their irregular menstrual cycle. [Menstrual regulation with medication] should not be available everywhere, without proper counseling, monitoring and regulating...."-Female counselor, age 39, phase one, urban area

\section{DISCUSSION}

This project-the first clinical study of the use of mifepristone-misoprostol for menstrual regulation in Bangladesh-demonstrates the feasibility of introducing the method into routine health services in a unique setting. Nearly all women with known outcomes had a successful menstrual regulation with mifepristone-misoprostol without need for a surgical evacuation. Women also reported a high level of satisfaction with the method.

The menstrual regulation success rate of $93 \%$ observed in this study is comparable to international experience with this regimen at gestational ages of 63 days or less since the last menstrual period, which has shown success rates of $93-98 \% .^{15-17,19,20}$ Our study demonstrates that the mifepristone-misoprostol regimen can be provided with existing staff and equipment in menstrual regulation services in Bangladesh. Midlevel providers assisted in the eligibility screening and postabortion follow-up, especially in the phase-two sites. Studies have shown that nonphysician providers can effectively and safely offer the method. ${ }^{21}$ The medication regimen was also provided safely and effectively without the use of routine ultrasound for assessment of eligibility or menstrual regulation outcome. Although all women were asked to provide a phone number for followup purposes, this did not inhibit study enrollment. Ongoing research is examining the use of phone follow-up or a self-assessment at home in lieu of a routine in-clinic visit. Such simplified protocols may be particularly advan- 
tageous in settings where travel to the health facility may be difficult or inconvenient.

Prior research has shown that women can safely and effectively administer misoprostol at home. ${ }^{22}$ Our study reaffirms this finding and, in fact, when given the choice, most women in the study chose to administer the misoprostol at home. The qualitative data from our study suggest, however, that women managing their menstrual regulation procedure at home initially increased provider anxiety. This is a common experience in other settings with the introduction of a novel method. However, provider anxiety often diminishes with increased confidence and experience with the method. ${ }^{23}$

Our study findings also suggest that acceptability among providers may increase over time as providers become more comfortable with providing menstrual regulation using medication. The introduction of medication menstrual regulation may require an adjustment in tasks, especially an increase in the need to provide information and counseling. The development of standardized counseling and informational materials for providers and women may help smooth this adjustment. Such materials may aid providers in counseling and help to allay provider concerns about women's ability to manage their care independently. These materials may also be a useful means of educating women and their networks about menstrual regulation with medication.

Attesting to the success of the national menstrual regulation program, women in Bangladesh often present early for menstrual regulation services. Approximately half of the women in the study had been amenorrheic for six weeks or less. However, without verification of pregnancy status with a urine pregnancy test (the standard clinical practice for eligibility assessment), there is the risk that some of these women may have been experiencing amenorrhea for reasons other than pregnancy. Our study suggests that the current practice of bimanual exam and patient history is relatively good at identifying women with ongoing pregnancy. We do not have comparative data for routine menstrual regulation services so we cannot speculate if this reflects the normal patient population in these clinics. We also cannot confirm whether the women with a negative pregnancy test were indeed not pregnant. The eligibility assessment did find that slightly fewer than half of these women were very early in pregnancy (i.e., six weeks or less since their last menstrual period). However, for most women who returned for follow-up, the clinical findings and history appear consistent with the expected course of treatment for a pregnant woman (i.e., a history of bleeding similar to or greater than menses and evidence of a decrease in uterine size consistent with a state of nonpregnancy). Also, two-thirds of the samples with negative test results came from three clinics (8-11 cases each; 30 of the 45 negative samples). In those clinics, most of the negative tests occurred in sequence (i.e., with no or only one intervening positive test); it is possible that an error in the laboratory could have resulted in false results.
Still, in this setting, it is possible that some women who did not have an ongoing pregnancy (and were experiencing amenorrhea for other reasons) received mifepristonemisoprostol for menstrual regulation. There are no adverse effects associated with taking mifepristone and misoprostol when not pregnant and, arguably, the ingestion of these medications is considerably safer than the alternative-the potential risk of infection associated with an unnecessary invasive evacuation of the uterus. However, the management of such cases is still of concern. While mifepristonemisoprostol may help reduce the risk of medically unnecessary surgical evacuations, it may not do so completely. One woman with amenorrhea of six weeks or less underwent a surgical evacuation on day five after she reported no bleeding following misoprostol administration. (Two women with positive pregnancy tests also received a surgical evacuation when they reported no bleeding at an unscheduled visit prior to follow-up.) Especially in settings where pregnancy status is not confirmed with a urine pregnancy test or ultrasound, providers should be advised to complete a physical exam at the scheduled follow-up visit before performing any additional interventions. Any widespread introduction of mifepristone-misoprostol should be accompanied by training, monitoring and evaluation, and other quality control measures to ensure appropriate and effective eligibility assessment and confirmation of final menstrual regulation status.

An interesting finding that emerged from the focus group discussions was the observation about the need to ensure quality and appropriate use if the drug regimen becomes widely available in Bangladesh. There is little regulation of pharmacies in Bangladesh and many medicines are sold over the counter without prescription. ${ }^{24}$ Pharmacies are allowed to sell oral contraceptives and emergency contraception without prescription. Several focus group participants suggested that menstrual regulation with medication should be made available in selected locations where the necessary counseling, referral and follow-up can be ensured. The concerns raised about the potential impact of widespread availability of the drugs in pharmacies reflected the recognition of the importance of increased counseling for menstrual regulation with medication.

The findings of the study should be assessed while considering the following limitation. The study sites were located in urban or periurban settings, which have relatively good infrastructure when compared with rural areas of the country. The findings may thus not be generalizeable to regions of Bangladesh where transportation services and referral networks are less developed. Future research should explore the use of mifepristone-misoprostol protocols in public-sector facilities where staff and resources may be more limited.

\section{REFERENCES}

1. Chowdhury SNM and Moni D, A situation analysis of the menstrual regulation programme in Bangladesh, Reproductive Health Matters, 2004, 12(24, Suppl):95-104. 
2. Johnston HB et al., Scaled up and marginalized: a review of Bangladesh's menstrual regulation programme and its impact, in: Blas E, Sommerfeld J and Kurup AS, eds., Social Determinants Approaches to Public Health: From Concept to Practice, Geneva: World Health Organization (WHO), 2011, pp. 9-24

3. Oliveras E et al., Situation Analysis of Unsafe Abortion and Menstrual Regulation in Bangladesh, Dhaka, Bangladesh: International Centre for Diarrhoeal Disease Research, Bangladesh, 2008.

4. Hossain A et al., Menstrual regulation, unsafe abortion and maternal health in Bangladesh, In Brief, New York: Guttmacher Institute, 2012, No. 3

5. Singh $\mathrm{S}$ et al., The incidence of menstrual regulation procedures and abortion in Bangladesh, 2010, International Perspectives on Sexual and Reproductive Health, 2012, 38(3):122-132.

6. Nanda P and Mishra A, Understanding the Determinants of Safe Abortion Services in Bangladesh: The Perspective of Users and Gatekeepers, London: International Planned Parenthood Federation, 2011.

7. Akhter $\mathrm{HH}$ et al., A Study to Assess the Determinants and Consequences of Abortion in Bangladesh, Dhaka, Bangladesh: Development Assistance Council and Bangladesh Institute of Research for Promotion of Essential \& Reproductive Health and Technologies, 1998.

8. Piet-Pelon NJ, Menstrual Regulation Impact on Reproductive Health in Bangladesh: A Literature Review, Bangladesh: Population Council, 1997.

9. Kamal GM and Begum SF, Study on Intervention Necessary for Preventing Rejection of MR Clients, Dhaka, Bangladesh: Bangladesh Association for Prevention of Septic Abortion, 1990.

10. Islam M, Rob U and Chakraborty N, Menstrual regulation practices in Bangladesh: an unrecognized form of contraception, AsiaPacific Population Journal, 2004, 19(4):75-99.

11. Johnston HB et al., Health system costs of menstrual regulation and care for abortion complications in Bangladesh, International Perspectives on Sexual and Reproductive Health, 2010, 36(4):197-204.

12. Gynuity Health Projects, Map of Mifepristone Approvals, 2012, $<$ http://gynuity.org/downloads/map_mife_en.pdf>, accessed Dec. 3, 2012.

13. Kulier $\mathrm{R}$ et al., Medical methods for first trimester abortion, Cochrane Database of Systematic Reviews, 2011, Issue 11, No. CD002855.

14. WHO, Safe Abortion Technical and Policy Guidance for Health Systems, second ed., Geneva: WHO, 2012.

15. Middleton T et al., Randomized trial of mifepristone and buccal or vaginal misoprostol for abortion through 56 days of last menstrual period, Contraception, 2005, 72(5):328-332.

16. Winikoff B et al., Two distinct oral routes of misoprostol in mifepristone medical abortion: a randomized controlled trial, Obstetrics E Gynecology, 2008, 112(6):1303-1310.

17. Fjerstad $\mathrm{M}$ et al., Effectiveness of medical abortion with mifepristone and buccal misoprostol through 59 gestational days, Contraception, 2009, 80(3):282-286.

18. Borgatta L et al., Instituting medical abortion services: changes in outcome and acceptability related to provider experience, Journal of the American Medical Women's Association, 2000, 55(3, Suppl.) 173-176.

19. Chong E et al., A randomized controlled trial of different buccal misoprostol doses in mifepristone medical abortion, Contraception, 2012, 86(3):251-256.

20. Blum J et al., Comparison of misoprostol-only and combined mifepristone-misoprostol regimens for home-based early medical abortion in Tunisia and Vietnam, International Journal of Gynaecology E Obstetrics, 2012, 118(2):166-171.

21. Warriner IK et al., Can midlevel health-care providers administer early medical abortion as safely and effectively as doctors? A randomised controlled equivalence trial in Nepal, Lancet, 2011, 377(9772):1155-1161.
22. Winikoff B et al., Safety, efficacy and acceptability of medical abortion in China, Cuba and India: a comparative trial of mifepristonemisoprostol versus surgical abortion, American Journal of Obstetrics \& Gynecology, 1997, 176(2):431-437.

23. Ellertson $C$ et al., Providing mifepristone-misoprostol medical abortion: the view from the clinic, Journal of the American Medical Women's Association, 1999, 54(2):91-96.

24. Babu MM, Factors contributing to the purchase of over the counter (OTC) drugs in Bangladesh: an empirical study, The Internet Journal of Third World Medicine, 2008, vol. 6, issue 2, doi: 10.5580/1017, <http://www.ispub.com/journal/the-internet-journalof-third-world-medicine/volume-6-number-2/factors-contributingto-the-purchase-of-over-the-counter-otc-drugs-in-bangladesh-anempirical-study.html\#sthash.NkQgRGQB.dpbs>, accessed May 1, 2012

\section{RESUMEN}

Contexto: Más de 700.000 mujeres recurren anualmente a la regulación menstrual o evacuación del útero con aspiración manual endouterina; muchas más recurren al aborto inseguro. El uso de píldoras para la evacuación del útero podría aumentar el acceso de las mujeres a servicios seguros de regulación menstrual y reducir con ello los altos niveles de morbilidad relacionada con el aborto y la regulación menstrual en Bangladesh.

Métodos: En 10 instituciones de salud en Bangladesh, 651 mujeres que dieron su consentimiento y que estaban buscando servicios de regulación menstrual, y para quienes habian transcurrido 63 días o menos desde su última menstruación, recibieron 200 mg de mifepristona seguida, después de 24 horas, por $800 \mathrm{mcg}$ de misoprostol bucal administrado en su hogar o en la clínica. Se recolectaron datos prospectivos para determinar la experiencia y satisfacción de las mujeres con el procedimiento, el resultado de la regulación menstrual, asi como los recursos humanos y físicos necesarios para proveer el método. Se llevaron a cabo discusiones de grupo focal con un grupo formado por una muestra intencional de proveedores de servicios en cada institución con el fin de comprender sus actitudes acerca de la introducción de la regulación menstrual con medicamentos.

Resultados: La mayoría (93\%) de las mujeres con resultados conocidos de regulación menstrual evacuaron el útero sin intervención quirúrgica. En general, la mayor parte (92\%) de las mujeres expresaron satisfacción con el uso de píldoras para su regulación menstrual. Por su parte, los proveedores enfrentaron retos y preocupaciones iniciales, particularmente en relación a los requerimientos adicionales de consejería y la falta de control respecto al resultado final, pero adquirieron confianza después del uso exitoso del régimen de medicamentos.

Conclusiones: La combinación de mifepristona-misoprostol puede ofrecerse de manera segura dentro de los servicios existentes de regulación menstrual en áreas urbanas y periurbanas en Bangladesh, y tiene un alto nivel de aceptación entre las mujeres. Las preocupaciones iniciales de los proveedores de servicios disminuyen al aumentar la experiencia con el método.

\section{RÉSUMÉ}

Contexte: Chaque année, plus de 700 mille femmes font appel à la régulation menstruelle, ou évacuation utérine par aspiration sous vide; bien davantage ont recours à l'avortement 
non médicalisé. L'approche médicamenteuse de l'évacuation utérine pourrait accroître l'accès des femmes à des services de régulation menstruelle sans risques et faire baisser les hauts niveaux de morbidité imputables à l'avortement et à la régulation menstruelle au Bangladesh.

Méthodes: Dans 10 établissements du Bangladesh, 651 femmes consentantes en quête de services de régulation menstruelle et dont les dernières règles remontaient à un maximum de 63 jours ont reçu 200 mg de mifépristone suivis, 24 heures plus tard, de $800 \mathrm{mcg}$ de misoprostol, administrés par voie orale à domicile ou à la clinique. Des données prospectives ont été collectées pour déterminer l'expérience et la satisfaction des femmes à l'égard de la procédure, l'issue de la régulation menstruelle et les ressources humaines et matérielles nécessaires à l'offre de la méthode. Des discussions de groupe ont été menées avec un échantillon délibéré de prestataires de chaque site, afin de cerner leurs attitudes concernant l'introduction de la régulation menstruelle médicamenteuse.

Résultats: La majorité des femmes (93\%) aux issues de régulation menstruelle connues ont obtenu une évacuation utérine sans intervention chirurgicale. Dans l'ensemble, la plupart des femmes (92\%) étaient satisfaites de leur régulation menstruelle par voie médicamenteuse orale. Les prestataires ont dî faire face aux défis et inquiétudes initiaux, concernant notamment les exigences de conseil accrues et l'absence de contrôle sur l'issue finale, mais ils se sont montrés plus confiants après utilisation réussie du programme médicamenteux.

Conclusions: La combinaison de mifépristone-misoprostol peut être proposée sans risques au sein des services de régulation menstruelle existants des milieux urbains et périurbains du Bangladesh. Elle bénéficie d'un haut degré d'acceptabilité parmi les femmes. Les inquiétudes initiales des prestataires diminuent à mesure qu'ils acquièrent l'expérience de la méthode.

\section{Acknowledgments}

This research protocol and the preparation of this manuscript were funded by a grant from an anonymous donor to Gynuity Health Projects. icddr,b also gratefully acknowledges the following donors that provide unrestricted support: Australian Agency for International Development; Government of the People's Republic of Bangladesh; Canadian International Development Agency; Embassy of the Kingdom of the Netherlands; Swedish International Development Cooperation Agency; and the Department for International Development, UK. The Concept Foundation donated the mifepristone-misoprostol but did not contribute to the design or analysis of the study. Square Pharmaceuticals, Ltd. donated the analgesics to icddr, $b$ for the study but did not contribute to the design or analysis of the study.

Author contact: hbracken@gynuity.org 